\title{
El cine, una estrategia para desarrollar habilidades del pensamiento crítico en sociales
}

\section{The cinema, a strategy to develop critical thinking skills in social}

Fecha de recepción: 20 de Mayo de 2016.

Fecha de aprobación: 25 de Noviembre de 2016.

Artículo de Reflexión
Sandra Liliana Morantes Cepeda* Yasmin Gordillo Avila**

\section{Resumen}

El trabajo "El cine, una estrategia para desarrollar habilidades del pensamiento crítico en sociales" parte de una problemática encontrada en los estudiantes de los grados primero (109) y segundo (207) de la Sede Manitas de la Institución Educativa Politécnico Álvaro González Santana (IEPAGS) de la ciudad de Sogamoso, en la que se pudo observar que, en su aprendizaje cotidiano, no desarrollaban las habilidades de pensamiento crítico, como son: comprensión, interpretación y proposición. Con el fin de mejorar estas dificultades, se utilizaron diversas estrategias didáctico-pedagógicas, a través del cine, que permitieron desarrollar en ellos dichas habilidades. Esta investigación, se enmarcó en la metodología de investigación acción, con un enfoque cualitativo, que definió la ruta a seguir, en tres fases: diagnóstica, intervención y análisis e interpretación, facilitando en los estudiantes la recordación, contextualización y el fortalecimiento de su expresión escrita y oral sobre temas de Ciencias Sociales.

Palabras clave: pensamiento crítico, habilidades, cine, ciencias sociales.
*Institución Educativa Politécnico Álvaro González Santana- Boyacá, Colombia salimoc28@hotmail.com ***Institución Educativa Politécnico Álvaro González Santana- Boyacá, Colombia yasmin_gordillo1@hotmail. com

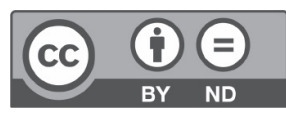




\section{Abstract}

The paper "Films, a strategy to develop critical thinking skills in social sciences" begins of a problem found in first and second grade students of the Manitas campus of the Educational Institution "Álvaro González Santana” (IEPAGS) in Sogamoso (Boyacá, Colombia) in which it was observed that in their daily learning, they did not develop critical thinking skills, such as: comprehension, interpretation and proposition. In order to improve these difficulties, various didactic-pedagogical strategies were used, through films, which allowed them to develop these skills. This research was framed in the action research methodology, with a qualitative approach, which defined the path to follow, in three phases: diagnosis, intervention and analysis and interpretation, facilitating in the students the remembrance, contextualization and the strengthening of their written and oral expression on topics of Social Sciences.

Keywords: critical thinking, skills, Films, science. 


\section{Introducción}

\section{"El cine es un instrumento del pensamiento y de la emoción" Ambrós \& Breu (2007)}

Como docentes de Ciencias Sociales de la Institución Educativa Politécnico Álvaro González Santana (IEPAGS) de Sogamoso, desde nuestra práctica pedagógica diaria, hemos visto algunos problemas relacionados con la apropiación de habilidades de pensamiento crítico en estudiantes de primero y segundo de primaria de la Sede Manitas.

En esa medida, se propuso responder al siguiente interrogante ¿De qué manera el cine promueve el desarrollo de habilidades de pensamiento crítico en los estudiantes de los grados primero (109) y segundo (207), en la asignatura de Ciencias Sociales de la Sede Manitas de la IEPAGS? Así, con miras a buscar respuestas, se hizo un rastreo bibliográfico de algunos trabajos, tesis y estudios referentes al tema, que dan cuenta de la importancia del cine como herramienta útil en el desarrollo de habilidades de pensamiento crítico en los estudiantes.

Con este propósito, para hablar del cine como herramienta que facilita el desarrollo del pensamiento crítico, está la tesis de Vargas (2014) de la Universidad Católica de Manizales de la Facultad de Educación para obtener título de Maestría en Educación, titulada "Posibles incidencias del área de Ciencias Sociales sobre el pensamiento crítico de estudiantes de básica y media del GI School del municipio de Salento - Quindío", quien afirma que "el lugar ocupado por las Ciencias Sociales al interior de los currículos escolares sugiere que, desde el área, los jóvenes, al menos en teoría, deben fortalecer la capacidad de reconocerse como sujetos históricos, actores dinámicos en roles por acuerdo, conocedores de su realidad, empoderados de competencias y habilidades sociales que les permitan actuar en contexto.” (p. 32).

De lo anterior, surge la apremiante necesidad de revisar y evaluar las posibles respuestas que está dando esta área del currículo, a las necesidades específicas en el momento de los jóvenes, como en el caso del anterior estudio; y ya en el terreno que compete a esta investigación, ver si atiende a las necesidades de los niños de 109 y 207 en la IEPAGS, que son estudiantes que están en edades entre los 6 a 8 años, además, revisar si el área facilita retomar el pasado desde revisiones socio-históricas que permitan al estudiante asumir posturas críticas y valorativas de su realidad.

En este mismo sentido, se encontró un artículo titulado "El desarrollo de las habilidades de pensamiento en el programa filosofía para niños", del Profesor Zabala (2014) de la Licenciatura en Filosofía de la UPTC Tunja, donde refiere que:

Adquirir y trabajar desde el concepto de habilidades de pensamiento, es buscar herramientas que como docentes podamos innovar y ayudarles a nuestros estudiantes a pensar por sí solos, a buscar una educación que también se interese más por el desarrollo del pensa-
Como docentes de Ciencias Sociales de la Institución Educativa Politécnico Álvaro González Santana (IEPAGS) de Sogamoso, desde nuestra práctica pedagógica diaria, hemos visto algunos problemas relacionados con la apropiación de habilidades de pensamiento crítico en estudiantes de primero y segundo de primaria de la Sede Manitas. 
no puede llegar a aventurar con sus estudiantes sino que debe vivenciar primero los procesos que pueden surgir a partir de la lectura de un texto, un cuento, una novela, una obra de arte, una película... miento en los estudiantes, que se les pueda brindar otras opciones para enriquecer y volver más dinámica los espacios en las aulas de clase [...] (p. 64).

Además, reflexiona sobre la necesidad de que el docente tenga una previa preparación y vivencie los procesos que pueden llegar a surgir de la experiencia al aplicar o utilizar una herramienta en el trabajo con los niños y niñas; y, en este sentido, afirma Zabala que el docente "no puede llegar a aventurar con sus estudiantes sino que debe vivenciar primero los procesos que pueden surgir a partir de la lectura de un texto, un cuento, una novela, una obra de arte, una película...” (p. 69), con la pretensión de que el maestro pueda contribuir, con previa preparación, al desarrollo de las habilidades de pensamiento de una manera que estimule y anime a los estudiantes cuando estos pregunten, cuestionen, reflexionen $\mathrm{u}$ opinen sobre algunos planteamientos dados sobre los temas propuestos.

Así también, se encontró un artículo producto de una investigación, titulada: "Incidencia de un programa de intervención pedagógica basado en habilidades de pensamiento críticoreflexivo y aprendizaje cooperativo en la competencia socioemocional de estudiantes de la básica de la ciudad de Medellín - Colombia” por la investigadora Rendón (2011), en cuyo resumen se dice:

Las condiciones de violencia y los problemas de convivencia escolar presentes en muchas de nuestras instituciones educativas motiva- ron el diseño y la implementación de un programa de intervención pedagógica basado en habilidades de pensamiento crítico reflexivo y aprendizaje cooperativo, orientado a la educación de la competencia socioemocional. [...] El estudio que se llevó a cabo es cuasiexperimental con aplicación de pretest y postest. Se concluye la urgente necesidad de reforzar operaciones intelectuales diversas en los estudiantes (aprehensión, análisis, síntesis, comparación, clasificación, asociación, conceptualización, entre otras) como única posibilidad de construir pensamiento racional e inteligente y potenciar la formación de estudiantes con un pensamiento crítico y autónomo. Esta es responsabilidad de todas las áreas del currículo, especialmente de aquellas clasificadas dentro de las ciencias sociales o humanas. (p. 105).

De esta manera, se pudo decir que el anterior estudio aportó a este propósito investigativo, "El cine una estrategia de desarrollo de habilidades de pensamiento crítico en ciencias sociales", validándolo en cuanto a la necesidad de contribuir al desarrollo de habilidades de pensamiento de orden superior, proporcionando herramientas a los niños y niñas, de tal forma que sean capaces de entender, analizar, encontrar y elegir la mejor solución a los problemas que se les puedan presentar en su vida escolar, familiar y social.

Por su parte, en la Universidad Pedagógica y Tecnológica de Colombia (UPTC) se encuentran algunos estudios relacionados con el cine como herramienta pedagógica. Es el caso de 
Guzmán (2014), quien para optar al título de magíster en Lingüística, en su tesis "Cineargumentando: Un modelo de argumentación para los estudiantes de educación media", realizó un trabajo donde a través del cine y el análisis de material fílmico se promueven procesos de argumentación; además, se tuvo en cuenta un trabajo investigativo que referencia Guzmán, donde se involucra el cine como herramienta pedagógica, realizado por Fanny Carolina Ortiz Pulido, quien en 2010 presentó en la tesis para optar el título de magíster en la UPTC, titulada "Yo aquí ahora. Del texto escrito al Audiovisual", del que Guzmán, dice:

[...] en la cual expone una serie de planteamientos y estrategias para abordar de manera coherente la lectura de textos que aportan otros sistemas de significación, es decir, mediante códigos icónicos como la fotografía, la escultura, la pintura y códigos sonoros como la música; argumentando que las mayores dificultades para un lector no versado en el tema, se presentan al tratar de reconstruir el significado del texto, ya que no llega a interpretar totalmente un enunciado, precisamente porque no advierte la connotación de muchos de estos códigos." (p. 16).

De esta manera, se reitera el interés que se tiene en esta investigación, para apoyar la enseñanza y el aprendizaje de temáticas de las ciencias sociales con otros sistemas de significación (textos icónicos), como es el caso del material fílmico que puede resultar atractivo para los estudiantes, facilitando la relación de sus mensajes con los contextos de los niños de este estudio, y propendiendo por el desarrollo de habilidades de pensamiento crítico en ellos.

Por lo tanto, en el proceso enseñanzaaprendizaje se pretende potencializar destrezas en los estudiantes que generen en ellos aprehensión de conocimientos con sentido crítico, mediante algunas actividades concretas que buscan incentivar el desarrollo de habilidades de pensamiento de manera lúdica, tomando el cine como estrategia de aprendizaje en la asignatura de Ciencias Sociales.

Es así, como, este artículo de reflexión se centrará en dos elementos, que son: El cine en la educación y De la teoría a la práctica... luces, cámara, jacción!, que llevan a ver al cine con gran expectativa, ya que en el proceso enseñanzaaprendizaje despierta interés, facilita la creatividad y proporciona herramientas para desarrollar la capacidad cognitiva y reflexiva, que enriquece las habilidades de pensamiento crítico y el aprendizaje significativo, tanto en estudiantes como en docentes.

\section{- El cine en la educación}

Con base en lo anterior, se evidencia que no es suficiente impartir conocimientos para lograr que los estudiantes argumenten con respecto a los temas que se trabajan, como lo menciona López (2013) en su artículo "Pensamiento crítico en el aula", quien cita a Nickerson (1988), en donde afirma que "aunque el conocimiento es esencial para el desarrollo del pensamiento, esto no garantiza el
Es así, como, este artículo de reflexión se centrará en dos elementos, que son: El cine en la educación y De la teoría a la práctica... 
El cine tiene el valor en $s$ mismo de ser transmisor de dramas humanos. Desde sus inicios, los relatos que cuenta el cine han afectado a generaciones de personas mediante sus argumentos, sus contenidos, sus imágenes y sus ideas. desarrollo de un pensamiento crítico" (p. 42). Se puede decir que el cine llevado al aula se constituye en una innovación que facilita desarrollar habilidades de pensamiento crítico, que pone en tela de juicio los conceptos tradicionales del aprendizaje.

Es así, que se convierte en una constante que los docentes, en su trabajo de aula, deben continuamente buscar nuevas estrategias didácticas para lograr en los estudiantes los aprendizajes exigidos por el Ministerio de Educación Nacional (MEN), además de los requerimientos de cada Institución y los intereses personales y socioculturales que exige el entorno en que se desenvuelve cada uno de los miembros de la comunidad educativa, por ello deben utilizar recursos lúdicos que pueden ser innovadores, porque aun estando ya hechos no se utilizan y pueden ayudar al mejoramiento del razonamiento crítico y a obtener mejores resultados.

Por consiguiente, con el propósito de fortalecer el desarrollo de habilidades de pensamiento crítico, se toma el cine, en el aprendizaje de las ciencias sociales en los estudiantes de primero (109) y segundo (207) de primaria de la IEPAGS, como estrategia que facilita el proceso cognitivo, siendo este el objetivo principal de esta investigación.

Muchas veces, escuchamos el término innovación y nos lleva a pensar en grandes cambios o cosas novedosas, pero en realidad el hecho de implementar en el proceso de enseñanza aprendizaje, una herramienta que ya existe, como lo es el cine, puede constituir una gran innovación por el impacto que genera y abrir nuevas perspectivas en el camino hacia el saber de los estudiantes.

De esta circunstancia, nace el hecho de que el cine, desde sus inicios, fue visto como parte de la diversión de los espectadores, evolucionando a través del tiempo, y se convirtió en memoria de cada época. Al respecto de este tema, Martinez-Salanova (2003) afirma que:

El cine tiene el valor en sí mismo de ser transmisor de dramas humanos. Desde sus inicios, los relatos que cuenta el cine han afectado a generaciones de personas mediante sus argumentos, sus contenidos, sus imágenes y sus ideas. El cine es cultura popular, arte y espectáculo. Las tramas y los temas del cine pueden y deben ser llevados a las aulas como elemento reflexivo y, por ende, orientador de comportamientos [...] Se incide en el valor de aprender de los otros, en la importancia del análisis de películas, en la introducción de los grandes temas que trata el cine y en su importancia en la adquisición de la sensibilidad hacia valores expresivos, cognoscitivos y expresivos. (párr. 1).

De esta manera, el cine recopila las vivencias de las comunidades en determinada época, acomodándose a cambios que le exigen los avances tecnológicos para, de esta manera, tener cautivado al público, de tal forma que brinde elementos para la reflexión social y cultural.

Es por esto, que se tomó el cine en cuanto a la educación, como una fuente para el aprendizaje, ya que es 


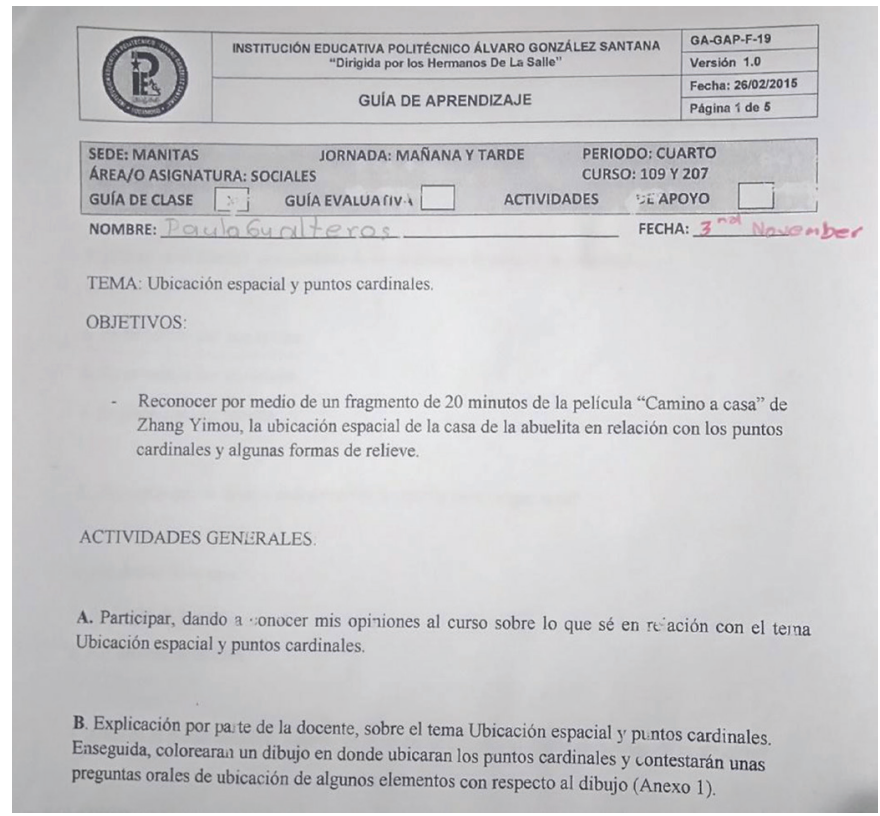

Figura A1. Taller escrito y oral. Tema: Ubicación espacial y puntos cardinales.

Fuente: elaboración propia.

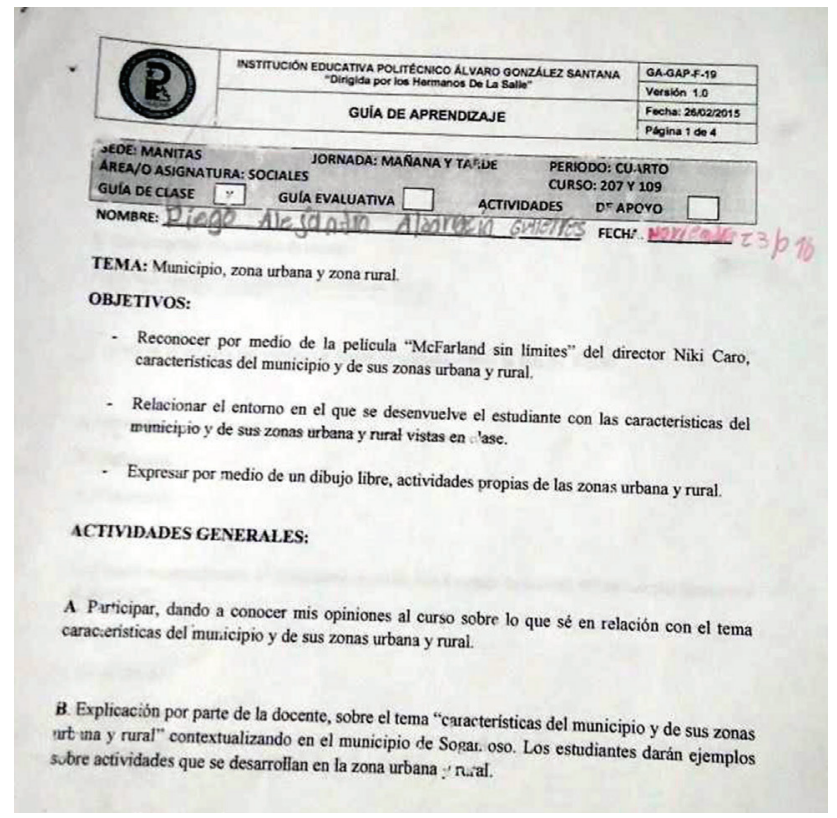

Figura A2. Taller escrito y oral. Tema: Municipio, zona urbana y zona rural.

Fuente: elaboración propia. considerado como recurso didáctico y ayuda para el docente en el aula, convirtiendo la fantasía en aprendizaje. Al respecto, Aparicio (2011) menciona que "el cine es una herramienta muy valiosa a la hora de educar, en el cual distingue tres niveles de aprendizaje desde el cine: aprender cine, aprender del cine y aprender con el cine" (pp. 2-3). El autor con estas tres formas de utilizar el cine, explica cómo, desde el aula de clase, se le debe enseñar al estudiante que el cine puede aportar a su proceso de aprendizaje, ya que se convierte en instrumento que le ayuda a potencializar procesos de comprensión, interpretación y proposición, brindando la posibilidad de transversalizar sus conocimientos, de tal forma que por medio del material cinematográfico se pudo enfatizar en algunas temáticas del plan de área y asignatura por período de la IEPAGS, como se muestra a continuación en la figura A1 y A2.

También, se puede deducir que el cine además de ser un recurso didáctico, ayuda a que los estudiantes se cuestionen y planteen reflexiones que den soluciones a problemáticas de su entorno, tanto escolar como familiar. Es así como, por medio del cine, se pudo desarrollar habilidades de pensamiento crítico en los estudiantes de los grados 109 y 207 de la IEPAGS, que les permitió dar ideas más completas de su vida cotidiana. De esta manera, pueden llevar las experiencias vividas y expresarlas, dando a conocer la imagen que proyecta el cine.

Es una constante que los docentes, en su quehacer pedagógico, deben continuamente buscar nuevas
También, se puede deducir que el cine además de ser un recurso didáctico, ayuda a que los estudiantes se cuestionen y planteen reflexiones que den soluciones a problemáticas de su entorno, tanto escolar como familiar. 
estrategias didácticas para lograr en los estudiantes los aprendizajes exigidos por el MEN, los requeridos en cada Institución, además de los intereses personales y sociales que exige el entorno sociocultural en que se desenvuelven estos procesos, por ello deben utilizar estrategias que pueden ser innovadoras porque aun estando ya hechas no se utilizan y pueden rendir buenos resultados; de esta forma, como lo señala OCENDI en su blog EDUCAMEDIA tratando el tema de la importancia del uso del cine como medio educativo para niños,

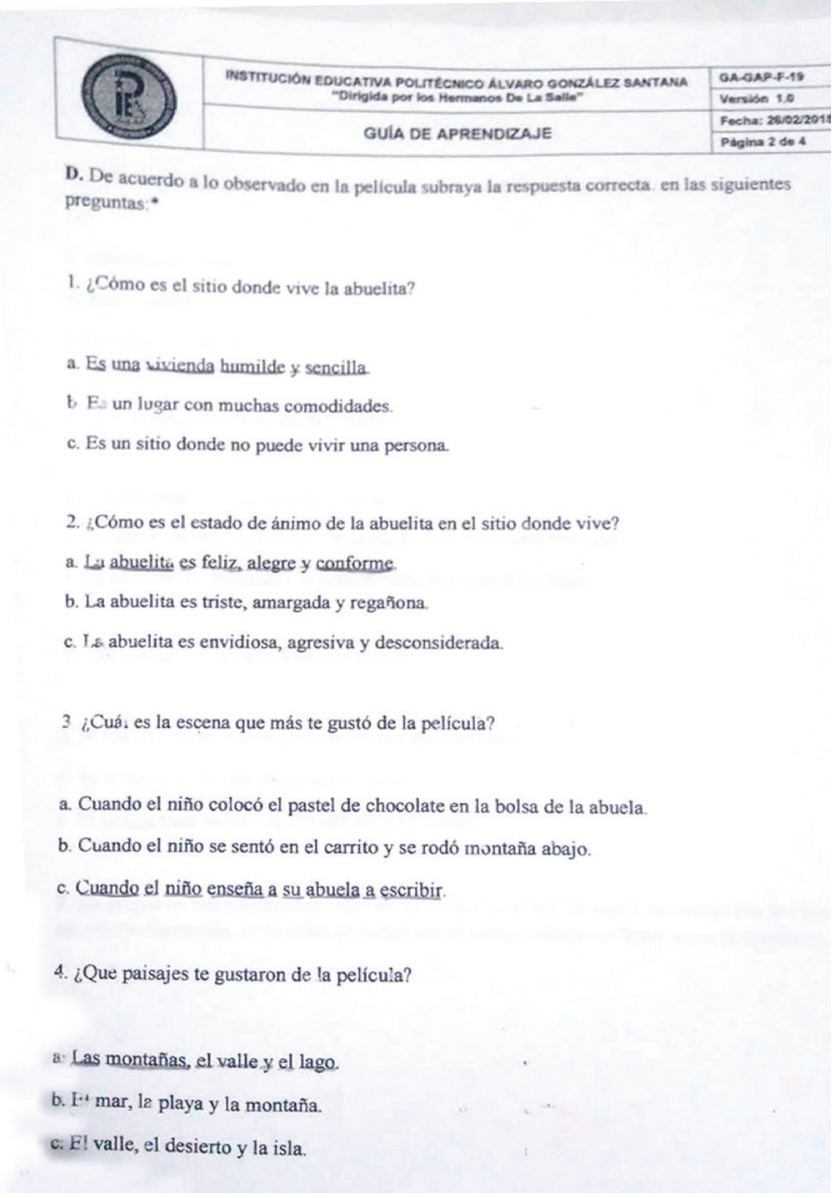

Figura A3. Desarrollo de taller escrito. Fuente: elaboración propia. el cine, empleado como fuente de información, permite adentrarse en el estudio de la sociedad, conocer culturas diferentes a la propia (interculturalidad), formar visiones en torno a acontecimientos pasados, presentes y futuros (nos permite juzgar, ponernos en el papel de los personajes históricos más relevantes y preguntarnos el porqué de sus actos y del devenir del mundo), entrar en contacto con valores, ideas, pensamientos, actitudes, normas [...] Estos y otros aspectos convierten al cine en un recurso más a disposición no solo del docente, sino también del currículum [...] (párr. 1 y 2).

Cabe anotar que, el cine permite al currículo, fortalecer desdela planeación, el trabajo del docente, en lo relacionado con las bases que se dan en primaria, además, por ser una estrategia didáctico - pedagógica, facilita el proceso de aprendizaje, como se evidenció en los estudiantes al utilizar películas para relacionarlas con temáticas del plan de estudios y conducirlos gradualmente a entenderlas, resolver situaciones de su contexto relacionadas en las actividades propuestas, y proponer sus puntos de vista en forma oral y escrita con una mayor coherencia.

Es por esto, que es significativa la importancia que tiene el docente como mediador en este proceso de adaptación. Sin embargo, es relevante resaltar que, como todo proceso, necesita de una preparación, para lograr decodificar 
el lenguaje que presenta cada una de las imágenes proyectadas y que los espectadores deben interpretar para reconstruir sin mayor dificultad, cada uno de los mensajes que emiten los recursos cinematográficos, en el proceso que se llevó a cabo, en la preparación de los talleres para trabajar con los estudiantes, en donde se evidenciaron resultados como la contextualización de los temas propuestos, por medio de películas.

De lo anterior, se infiere que el cine como recurso didáctico es un elemento que facilita a los estudiantes captar mensajes transmitidos con mayor facilidad de los filmes y que reflejan la realidad de una sociedad, desarrollando en ellos capacidades de interpretación y discernimiento que permiten fortalecer sus habilidades de pensamiento crítico.

Por tanto, es de vital importancia que el estudiante vaya ampliando su visión y sea autónomo en su aprendizaje, desarrollando de esta manera sus habilidades cognitivas y críticas, apoyado en los diversos recursos que le presenta el mundo cambiante, en este caso particular, el cine como estrategia de desarrollo de habilidades de pensamiento crítico en la asignatura de Ciencias Sociales.

Sin duda alguna, estos cambios generan mejoras en la calidad de la educación, ya que permite que el estudiante, a la vez, disfrute y aprenda en su proceso de aprendizaje, teniendo como base la articulación entre las temáticas propuestas y los innumerables recursos que están a su disposición en el medio cinematográfico, conduciéndolo inconscientemente al saber en un

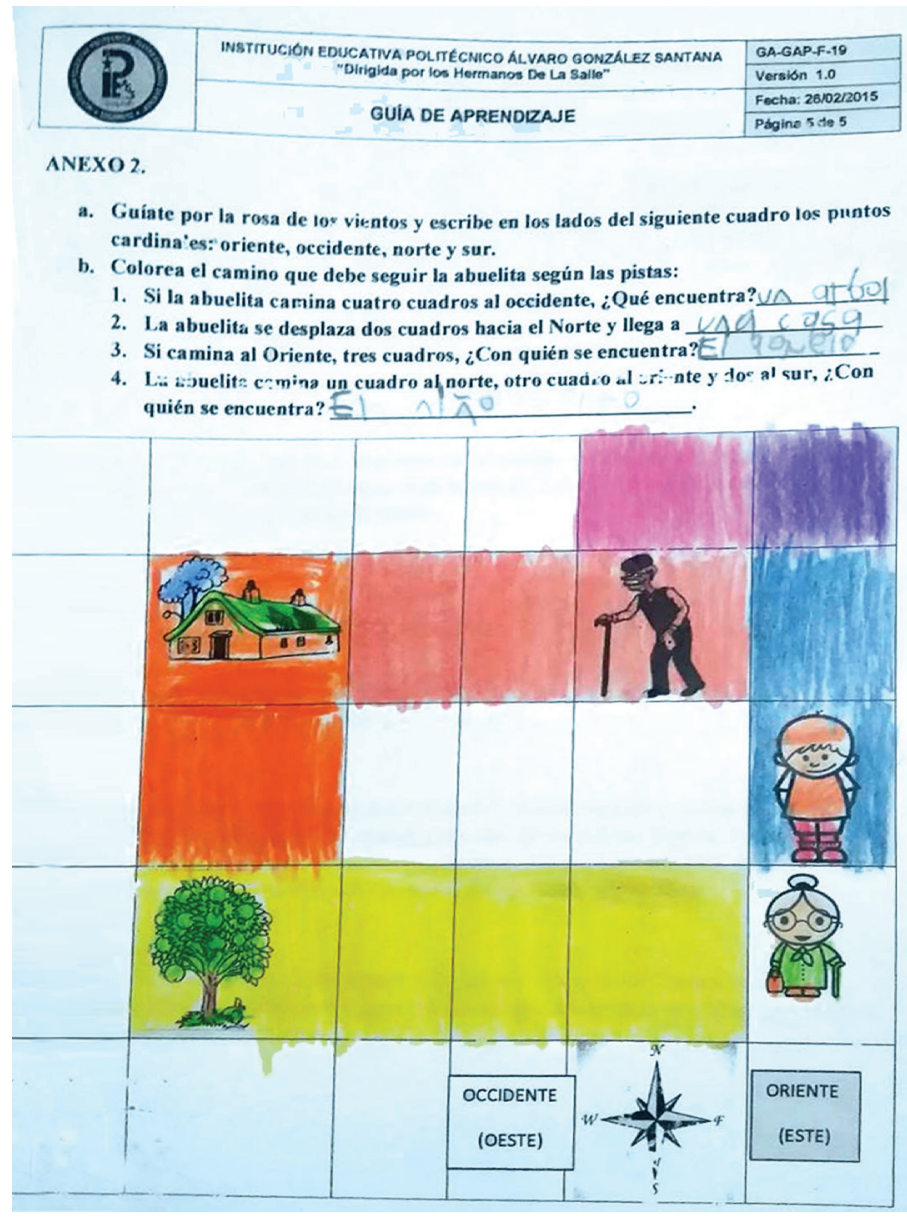

Figura A4. Ficha lúdica de trabajo colaborativo y puesta en común. Fuente: elaboración propia.

ambiente de aprendizaje más agradable y que le permite mayor resignificación en sus formas de actuar y pensar dentro de un grupo social. De acuerdo con lo anterior, Amar (2009) afirma que

[...] La educación ya no basta que contemple la formación con y en, sino que se hace prioritario una educación para los medios de comunicación. De este modo, los medios y las nuevas medias, incluyen desde, el cine hasta las nuevas formas de consumo que se están desarrollando en la actualidad [...] (p. 19). 
Es indudable que, el cine constituye una estrategia innovadora en el aprendizaje, dado que, además de ser una estrategia didácticopedagógica, facilita llevar a cabo procesos de hacer pensar y sentir, evocando en el espectador otros tiempos, momentos y circunstancias que hacen parte de la historia.
Pero, es importante resaltar también, que para los más pequeños, se hace necesario un proceso que conduzca a educar para el cine, puesto que no es suficiente ver cine por verlo, sino que esta actividad requiere de un ejercicio de percepción más profundo, donde el espectador, además de tener la posibilidad de disfrutar de las imágenes en movimiento, establece una situación de aprendizaje y de emoción, que progresivamente le facilitan la comprensión del entramado y del lenguaje que presentan.

Es indudable que, el cine constituye una estrategia innovadora en el aprendizaje, dado que, además de ser una estrategia didáctico-pedagógica, facilita llevar a cabo procesos de hacer pensar y sentir, evocando en el espectador otros tiempos, momentos y circunstancias que hacen parte de la historia. De esta manera, facilita la fijación de conocimientos y la práctica de valores y actitudes que conducen a despertar el sentido crítico y la creatividad, componentes que enriquecen el desarrollo de habilidades de pensamiento crítico en los estudiantes de los grados 109 y 207 de la IEPAGS.

Es así, que la educación tiene en el cine una herramienta que facilita desarrollar procesos que le permiten al espectador ver, analizar, interpretar y argumentar diferentes posturas, relacionarlas con la imagen, $y$ cuestionar las formas de actuar en ciertos momentos particulares que se muestran en la trama de las películas y que se relacionan con la temática de las Ciencias Sociales, aportando al proceso crítico del estudiante.
Las ciencias sociales, en algunas ocasiones, desde la práctica pedagógica, suele ser percibida como una asignatura a la que no se le da la relevancia que merece y es vista como complemento en el aula, aunque figure en la intensidad horaria del plan de área y asignatura por período. Pero es ella, un eje fundamental que facilita, con sus múltiples recursos y pretensiones, formar a través de sus temáticas, sujetos íntegros que se piensen en sus propias comunidades $\mathrm{y}$ analicen rumbos $\mathrm{y}$ eventos que son parte de la historia y la cultura.

Es así que, las Ciencias Sociales se constituyeron en pilar importante para que, en el trabajo de sus contenidos, se desarrollaran procesos de pensamiento que permitieron al estudiante ir alcanzando niveles de análisis y reflexión que fueron elementos importantes para el desarrollo de su capacidad crítica, comprensiva, interpretativa y propositiva, peldaño necesario para incursionar en el desarrollo de habilidades de pensamiento crítico.

Además, se encontró la necesidad de hacer converger el medio audiovisual, la educación y el desarrollo del pensamiento crítico en el aprendizaje de las ciencias sociales, donde el estudiante llevaba un proceso, que le permitió lograr la interacción de su capacidad analítica y reflexiva. Teniendo a favor una de las cualidades que menciona Barraza González (2015), en donde parafraseándolo, menciona que la mnemotecnia facilita el proceso mental por asociación para la fácil recordación, por tanto a los 
estudiantes les llama más la atención ver y leer imágenes (texto icónico), que leer texto escrito, ventaja que permite que absorban más rápido una gran cantidad de conocimientos en poco tiempo, para luego reflexionar libremente, establecer conclusiones y pensamientos propios, aspectos importantes que ayudan a fortalecer el desarrollo de habilidades de pensamiento crítico de los grados 109 y 207 de la sede Manitas de la IEPAGS.

- De la teoría a la práctica... luces, cámara, jacción!...

La propuesta investigativa se enmarca en un enfoque cualitativo, y el tipo de investigación que se trabajó fue la investigación acción, que facilitó centrar la atención de la actividad realizada en el aula y presentar gran variedad de estrategias didácticopedagógicas, que buscaron mejorar el quehacer pedagógico, en cuanto a habilidades de pensamiento crítico, dentro de la comunidad estudiantil, sustentados en las teorías de Kemmis (1988) y Elliott (1993).

Luego de definir la línea de investigación a seguir, se procedió a poner en marcha las técnicas para recolección de datos e información por medio de los instrumentos propuestos, que permitieron relacionar las teorías expuestas anteriormente, buscando que los estudiantes mejoren el desarrollo de las habilidades de pensamiento crítico. Cabe señalar que, este proyecto se ejecutó en tres fases que fueron: una de diagnóstico, otra de intervención $\mathrm{y}$, finalmente, una de análisis e interpretación. De esta forma, en un primer momento, se llevaron registros de las observaciones acerca de los acontecimientos en las prácticas de aula, que permitieron evidenciar falta de comprensión en los temas trabajados, poco interés por consultar y ampliar temáticas vistas en clase, dificultad para proponer ideas y soluciones a problemas presentados. Además, se aplicó una encuesta a padres de familia y estudiantes con el fin de indagar sobre el entorno familiar y el desempeño académico de los estudiantes. También, se preparó y aplicó un taller diagnóstico, con el objeto de ver el interés que despertaba en los niños, la utilización de material fílmico en temáticas de Ciencias Sociales.

En este caso, al hacer la interpretación de los registros tomados de la observación, se pudo notar que al no presentar un adecuado desarrollo de las habilidades de comprensión, interpretación y proposición, se obtuvo que un $80 \%$ de los estudiantes del grado 207 tienen dificultad para resolver, entender, analizar y presentar sus ideas y respuestas de manera coherente y dando una estructura gramatical adecuada, acorde a sus edades; y el restante $20 \%$ tiene un desempeño acertado frente a las mismas situaciones que se plantearon en el proceso propuesto.

Por su parte, el grado 109 presentó que un $85 \%$ de los estudiantes tienen dificultad al entender, analizar y responder de forma oral a situaciones relacionadas con la temática planeada y contextualizada con su realidad, mientras que un $15 \%$ expresó sus ideas de forma más organizada y con claridad, y las plasmó de manera escrita.
La propuesta investigativa se enmarca en un enfoque cualitativo, y el tipo de investigación que se trabajó fue la investigación acción, que facilitó centrar la atención de la actividad realizada en el aula y presentar gran variedad de estrategias didácticopedagógicas, 
De la intervención realizada a los dos grados $(207,109)$, se encontró que el cine despertó gran interés en los estudiantes al utilizarlo como recurso didáctico y estratégico para el desarrollo de habilidades de pensamiento crítico en el aprendizaje de las ciencias sociales
En una segunda etapa, se trabajaron los talleres escritos y orales, los conversatorios, lluvia de ideas y exposiciones de trabajos propuestos, utilizando películas comerciales, documentales y cortometrajes, explicando y unificando criterios referentes al significado de los contenidos conceptuales mínimos, y se enfatizó en la importancia de prestar especial atención al argumento y toda la información proyectada en la película, para luego resolver las actividades propuestas, con el fin de brindar elementos que les permitió mostrar sus habilidades de pensamiento crítico por medio del cine como estrategia de enseñanza y aprendizaje de algunos temas en Ciencias Sociales, en donde los estudiantes debían entender, contextualizar, analizar, preguntar, resolver, crear y proponer, dando soluciones a situaciones presentadas en diferentes actividades propuestas en el plan de área y asignatura de la Institución.

Finalmente, en una tercera etapa, se procedió a revisar, clasificar y analizar los resultados obtenidos en cada una de las actividades aplicadas, para determinar si se logró el objetivo de esta investigación y en qué medida.

Posterior a esto, se procedió a poner en movimiento las ideas. Como lo menciona Amar (2009), "[...] también le atribuimos (al diálogo) la capacidad de discernir y alcanzar el conocimiento gracias a la participación a través de preguntas y respuestas, algo que propicia el movimiento de las ideas" (p. 25); trabajando la capacidad de discernir, analizar y explicitar posturas extraídas de lo observado en el filme, a través de preguntas y respuestas, utilizando de este modo el diálogo como un elemento indispensable, sobre el cual se soporta el desarrollo de habilidades de pensamiento crítico en la asignatura de Ciencias Sociales de la sede Manitas de la IEPAGS.

Fue así como, en el grado 207, se evidenció que los estudiantes progresivamente fueron mejorando sus argumentos, exposición de propuestas, defensa de ideas y contextualización de los temas trabajados, según plan de estudios. Por su parte, el grado 109 mostró mejoría paulatina en la construcción asertiva de respuestas orales y escritas, una mayor comprensión y relación de los temas con el contexto y les facilitó expresarse con más fluidez frente a sus compañeros.

De la intervención realizada a los dos grados $(207,109)$, se encontró que el cine despertó gran interés en los estudiantes al utilizarlo como recurso didáctico y estratégico para el desarrollo de habilidades de pensamiento crítico en el aprendizaje de las ciencias sociales, donde como estrategia pedagógica incentivó e hizo más llamativo el aprendizaje, logrando un mejor nivel de comprensión, interpretación y proposición que se reflejó en la puesta en común, evidenciado a través de la observación directa, donde se percibieron a los estudiantes más receptivos y participativos en cada una de las pruebas aplicadas. De este trabajo, se obtiene como aporte importante, que el cine utilizado como estrategia didáctico-pedagógica en la asignatura de Ciencias Sociales de los grados 109 
y 207 de la sede Manitas de la IEPAGS, favoreció el aprendizaje y el desarrollo de las habilidades comprensiva, interpretativa y propositiva del pensamiento crítico.

\section{Conclusiones}

Al culminar la etapa inicial de esta experiencia de investigación, en donde se trabajó con el cine como estrategia de pensamiento crítico en el aprendizaje de las ciencias sociales, se puede concluir que:

El cine es un recurso didáctico y llamativo, que despierta y enriquece las competencias y habilidades de discernimiento, análisis y reflexión de situaciones humanas. Se apoya en el diálogo, para generar procesos comunicativos que ponen al espectador en el otro lado, es decir, ya no en una actitud pasiva, sino con un posicionamiento activo, crítico y responsable como miembro de un grupo social (familia, amigos y barrio).

Además, el recurso cinematográfico, por ser un poderoso medio informativo por el cual se accede a conocimientos culturales, históricos, científicos, entre otros, estimula el desarrollo de competencias básicas que fortalecen los conocimientos en las ciencias sociales, y genera responsabilidades y capacidades para la participación, aspectos observados en el momento de la aplicación de talleres en los estudiantes de los grados 109 y 207 de la sede Manitas de la IEPAGS.

Sin embargo, la actividad docente debe alimentar su quehacer con la implementación de la investigación y la puesta en marcha de nuevos conceptos $\mathrm{y}$ tendencias, que busquen redefinir la labor pedagógica para que vaya más allá de la transmisión de conocimientos y ayude a la construcción significativa de los saberes en los educandos. Es por esto que, la investigación debe acompañar al estudiante en el proceso de enseñanza aprendizaje, para que desde las aulas se incentive a que ellos generen preguntas sobre sus intereses e indaguen sobre la realidad de su entorno, y contextualicen los conocimientos aprehendidos.

De esta forma, se hace necesario crear un punto de convergencia entre la teoría y la práctica. Paulo Freire (1995), al respecto, escribió: "me preocupa la creciente distancia entre la práctica educativa y el ejercicio de la curiosidad epistemológica" (p. 81), buscando transformaciones en el quehacer diario del docente con sus estudiantes en el aula para derrotar limitaciones que se presentan en el proceso de aprendizaje, como la falta de atención, el desinterés y la no profundización en el conocimiento, aspectos que impiden el desarrollo de habilidades de pensamiento crítico, es por esto que se hace necesario que se implementen estrategias didácticopedagógicas que complementen la teoría que se ve en el aula.

Más aún, por medio de innovaciones pedagógicas ya existentes, como lo es el cine, se logró captar la atención en los niños y conducirlos al aprendizaje, de tal manera que llegaron al conocimiento de una manera lúdica y didáctica, donde hubo mayor aprehensión, interpretación, análisis y argumentación desde diferentes posturas y temas de su realidad y entorno.
El cine es un recurso didáctico y llamativo, que despierta y enriquece las competencias y habilidades de discernimiento, análisis y reflexión de situaciones humanas. 


\section{Referencias}

Ambrós, A. y Breu, R. (2007). Cine y educación: el cine en el aula de primaria y secundaria. Barcelona: editorial Grao.

Amar, V. M. (2009). El cine y otras miradas. Contribución a la educación y a la cultura audiovisual. Sevilla: Comunicación social ediciones y publicaciones.

Aparicio, D. (2011). El uso del cine como recurso didáctico. Una experiencia de educación mediática desde el Instituto de Tecnologías Educación. Recuperado el 12 de marzo de 2013, de http://www.educacionmediatica.es/comunicaciones/Eje\%202/ Daniel\%20Aparicio.pdf

Barraza, C. E. (2015). El cine como recurso didáctico en la enseñanza de las ciencias sociales. México, D.F.: Boletín UNAM-DGCS-390 Ciudad Universitaria.

ElLIOTT, J. (1993) El cambio educativo desde la investigación acción. Madrid: Morata.

Freire, P. (1995). A sombra desta mangueira. São Paulo: Olho d'Água.

GuZMán, M.C. (2014), Cineargumentando: Un modelo de argumentación para los estudiantes de educación media. (Tesis de Maestría). Universidad Pedagógica y Tecnológica de Colombia, Tunja, Colombia. Recuperado el 12 de abril de 2016, de https:// es.slideshare.net/ejcaroruiz1/cata-apuntes-fabis

Kemmis, S., \& MctagGarT, T. (1988) Cómo planificar la investigación acción. Barcelona Laertes. López, G. (2013). Pensamiento crítico en el aula. Docencia e Investigación, 37(22), 41-60. Recuperado el 15 de abril de 2016, de educacion.to.uclm.es/pdf/ revistaDI/3_22_2012.pdf

Martínez-Salanova, E. (2003). El valor del cine para aprendery enseñar. Recuperado el 12 de abril de 2016, de http://www.uhu.es/cine.educacion/articulos/valor_cine_ aprender_ensenar.htm

OCENDI (s.f.). EDUMEDIA. La importancia del uso del cine como medio educativo para niños. Recuperado el 12 de abril de 2016, de http://www.ocendi.com/educamedia/ la-importancia-del-uso-del-cine-como-medio-educativo-para-ninos/

RENDÓN URIBE, M. A. (2011). Incidencia de un programa de intervención pedagógica basado en habilidades de pensamiento crítico-reflexivo y aprendizaje cooperativo en la competencia socioemocional de estudiantes de la básica de la ciudad de Medellín-Colombia. Revista Virtual Universidad Católica del Norte, (32), 104-128. Recuperado el 3 de abril de 2016, de http://revistavirtual.ucn. edu.co/index.php/RevistaUCN/article/view/28/61

Vargas Escobar, L. A. (2014). Posibles incidencias del área de Ciencias Sociales sobre el pensamiento crítico de estudiantes de básica y media del GI School del municipio de SalentoQuindío. (Tesis de Maestría). Universidad Católica, Manizales, Colombia. Recuperado el 3 de abril de 2016, de http://repositorio.ucm.edu.co:8080/ jspui/bitstream/handle/10839/969/Leonardo\%20Andres\%20Vargas\%20 Escobar.pdf?sequence $=1$

Zabala, H. A. (2014). El desarrollo de las habilidades de pensamiento en el programa de filosofía para niños, Semillero del Grupo de Investigación Filosofia, Sociedad y Educación. Espiral, Revista de Docencia e Investigación, 4 (1), 59-70. Recuperado el 3 de abril de 2016, de http://revistas.ustabuca.edu.co/index.php/ESPIRAL/article/ view/551/446 